\title{
Bilingual Dictionaries, the Lexicographer and the Translator
}

\author{
Rachélle Gauton, Department of African Languages, University of Pretoria, \\ Pretoria, Republic of South Africa (rachelle.gauton@up.ac.za)
}

\begin{abstract}
This article focuses on the problems, and advantages and disadvantages of the bilingual dictionary from both the lexicographer's and the translator's point of view, with specific reference to bilingual Zulu dictionaries. It is shown that there are many and varying problems the lexicographer has to deal with and take cognisance of when compiling a translation dictionary. Of these, the main problem is the basic lack of equivalence or anisomorphism which exists between languages. This non-equivalence between languages is also the root cause of the difficulties with which the translator or user of the bilingual dictionary has to contend. The problems experienced by translators therefore overlap to a great extent with those which the lexicographer experiences in compiling a bilingual dictionary. It is concluded that the user of a bilingual dictionary should not only know what to expect to find in a translation dictionary, but must also treat such a dictionary with caution and discernment. It is also shown that there are clear criteria which the lexicographer can follow in compiling a bilingual dictionary, which would then enable the user (and in particular the translator as user) to disambiguate the recorded information successfully.
\end{abstract}

Keywords: BILINGUAL DICTIONARIES, LEXICOGRAPHER, TRANSLATOR, ISIZULU, PROBLEMS EXPERIENCED BY LEXICOGRAPHERS, PROBLEMS EXPERIENCED BY TRANSLATORS, NONEQUIVALENCE BETWEEN LANGUAGES, CHARACTER, SHORTCOMINGS AND ADVANTAGES OF BILINGUAL DICTIONARIES

Opsomming: Tweetalige woordeboeke, die leksikograaf en die vertaler. Die fokus van hierdie artikel is op die probleme, en voor- en nadele van die tweetalige woordeboek vanuit die oogpunt van sowel die leksikograaf as die vertaler, met spesifieke verwysing na tweetalige Zuluwoordeboeke. Daar word aangetoon dat daar baie en uiteenlopende probleme is waaraan die leksikograaf moet aandag gee en waarvan hy/sy moet kennis neem by die samestelling van ' $n$ vertalende woordeboek. Die vernaamste van hierdie probleme is die basiese gebrek aan ekwivalensie of anisomorfisme wat tussen tale bestaan. Hierdie nie-ekwivalensie tussen tale is ook die grondoorsaak van die moeilikhede waarmee die vertaler of gebruiker van die tweetalige woordeboek moet worstel. Die probleme ondervind deur vertalers oorvleuel dus tot 'n groot mate met dié wat die leksikograaf ondervind by die samestellling van 'n tweetalige woordeboek. Daar word tot die slotsom gekom dat die gebruiker van 'n tweetalige woordeboek nie net moet weet wat om van 'n vertalende woordeboek te verwag nie, maar ook so 'n woordeboek omsigtig en oordeelkundig moet benader. Daar word ook getoon dat daar duidelike kriteria bestaan wat die leksikograaf kan volg by die samestelling van ' $n$ tweetalige woordeboek wat die gebruiker (en veral die vertaler as gebruiker) dan in staat sal stel om die opgetekende inligting suksesvol te interpreteer.

Sleutelwoorde: TWEETALIGE WOORDEBOEKE, LEKSIKOGRAAF, VERTALER, ISIZULU, PROBLEME ERVAAR DEUR DIE LEKSIKOGRAAF, PROBLEME ERVAAR DEUR DIE VERTALER, NIE-EKWIVALENSIE TUSSEN TALE, AARD, GEBREKE EN VOORDELE VAN TWEETALIGE WOORDEBOEKE 


\section{Introduction}

This article focuses on the problems, advantages and disadvantages of the bilingual dictionary from both the lexicographer's and the translator's point of view, with specific reference to bilingual Zulu dictionaries.

Manning (1990: 159) indicates that the bilingual dictionary is the translator's basic tool, and that it is the bridge that makes interlingual transfer possible. Pinchuck (1977: 223) warns, however, that the bilingual dictionary is an instrument that has to be used with circumspection and discernment. Pinchuck (1977: 231) further cautions:

The bilingual dictionary has a particular importance for the translator, but it is also a very dangerous tool. In general when a translator needs to resort to a dictionary to find an equivalent he will do better to consult a good monolingual dictionary in the SL (source language - RG) and, if necessary, one in the TL (target language - RG) as well. The bilingual dictionary appears to be a short cut and to save time, but only a perfect bilingual dictionary can really do this, and no bilingual dictionary is perfect.

Swanepoel (1989: 202-203) agrees that it is a misconception to assume that the general bilingual dictionary is sufficiently sophisticated to be an ideal aid for professional translators. It is merely a useful, albeit a limited, aid. Swanepoel argues that the bilingual dictionary is limited for the following two reasons:

(a) It does not contain sufficient information for the user.

(b) It cannot be a substitute for the user's competence in the SL and TL. The process of translation involves the user's total communicative competence, which also includes a grasp of the text's sociocultural context.

Swanepoel concludes that the bilingual dictionary is nothing more than an aid to professional translators in cases where their acquired knowledge of the TL is lacking.

In this article, the reasons for this state of affairs will be elucidated by indicating

(a) which problems are experienced by the lexicographer in the compilation of the bilingual dictionary, with specific reference to Zulu; and

(b) which problems are experienced by the translator when attempting to find suitable translation equivalents by consulting the bilingual dictionary.

\section{Problems experienced by lexicographers}

According to Nida (1958: 279), the semantic problems involved in bilingual dictionaries are different from, and also more complicated than those encountered in the compilation of monolingual dictionaries. The reason for this is that 
whereas monolingual dictionaries are prepared for users who participate in and understand the culture being described, bilingual dictionaries describe a culture which differs in various proportions from that of the users.

There are many and varying problems the bilingual lexicographer has to deal with and take cognisance of when compiling a translation dictionary. Of these, the main problem would seem to be the basic lack of equivalence or anisomorphism which exists between languages, and this is the issue that will mainly be focused on in this article.

\section{The lack of equivalence between languages}

Writers such as Zgusta (1971), Pinchuck (1977), Nelson (1978), Al-Kasimi (1983), Swanepoel (1989), Mtuze (1990), Neubert (1992), Baker and Kaplan (1994), Gouws (1996) and Adamska-Sałaciak (2006) point out that there is a basic lack of equivalence or anisomorphism between languages. Zgusta (1971: 296) argues that a lack of equivalence can be manifested by any component of the lexical meaning, in any degree and dimension.

Baker and Kaplan (1994: 7) contend that equivalence is nebulous in nature, and cannot be represented by way of neat translation equivalents as is found in some conventional bilingual dictionaries. They point out that in interlingual communication, the same word, even with the same 'meaning', will have different equivalents in different contexts. Equivalence, therefore, is contextbound. Baker and Kaplan (1994: 8) further indicate that the problem of nonequivalence extends beyond the lexical level to the syntactic level. Although a certain syntactic structure may have an exact equivalent in another language, the equivalent structure may serve a different rhetorical purpose.

Zgusta (1971: 296) points out that very few equivalent words with no polysemy in either the SL or the TL have precisely the same meaning. He mentions that in the majority of cases such words are defined scientific terms. Zgusta (1971: 312) further indicates that usually the lexical meaning of the unit in the TL is only partly identical with that of its counterpart in the SL. The term 'partial equivalent' is therefore more appropriate than the term 'equivalent'.

Zgusta (1971: 319), as well as Al-Kasimi (1983: 60), indicates that there are basically two types of translations of entries found in a bilingual dictionary. These two types are:

(1) Translational / insertable equivalents, e.g. Zulu umhlangano English meeting / assembly

(2) Explanatory / descriptive equivalents, e.g.

Zulu ibandla English assembly of men (for discussion, as to hear a trial or an announcement of the chief)

The difference between these two types of equivalents is that whereas the translational equivalent, i.e. assembly / meeting, can immediately be inserted 
into a TL sentence, the explanatory equivalent, i.e. assembly of men, cannot always be directly inserted into a TL sentence. Al-Kasimi (1983: 60) points out that a further distinction can be made between an 'explanatory equivalent' and an 'explanation'. Where an explanation tends to be similar to a definition or description, an explanatory equivalent tends to approximate a translational unit that might be standardised by acceptance and use in the language, e.g. assembly of men (for discussion, as to hear a trial or an announcement of the chief) (Doke et al. 1990: 64). In this example, 'assembly of men' is an explanatory equivalent, whilst the phrase in parenthesis constitutes an explanation.

Zgusta (1971: 319) indicates that the main characteristic of a translational equivalent is that it must have the ability to be used in a fluent, good translation of whole sentences, and therefore to be inserted into contexts of the TL. The explanatory equivalent, on the other hand, gives more information about the lexical unit of the TL. Zgusta (1971: 321) further points out that an explanatory equivalent makes considerable demands on the user's knowledge of the TL. Zgusta (1971: 322) states that it is the lexicographer's task to indicate the most general translational equivalents that have a broader range of application which, with their glosses, correspond to the multiple meaning of the lexicographical unit of the SL. He concludes that the explanatory and translational equivalents are therefore not as opposed as may be thought at first glance, although the translational equivalent is always a possible, and sometimes the best possible, choice for insertion into a real sentence. As translational equivalents can be directly employed, Al-Kasimi (1983: 61) indicates that such equivalents should be favoured in a bilingual dictionary aimed at speakers of the SL as an aid to produce the TL.

Al-Kasimi (1983: 61) asserts that an explanatory equivalent works well if the TL is the user's mother tongue, as such an explanatory equivalent may suggest to, or elicit from, the user another equivalent which fits the particular context.

Neubert (1992: 6) argues that translational equivalents should constitute not primarily translations, but rather carefully selected prototypical lexical patterns. They would consequently function as a type of springboard, supplying translational starting points from which adequate equivalents can be found. Users are therefore expected to put in the extra work to find the most suitable equivalent, based on their native competence. Neubert (1992: 12) states:

A prototype does not claim to be the one and only translation, that would be fiction, it is intended to lead the user to the translation that is textually compatible, i.e. that fits grammatically, lexically, stylistically, pragmatically. A prototype, then, is a kind of cognitive schema, a lexical model. It supplies a potential translation, not the typical or even the ideal translation. It gives the user a clear notion of one sense of a word without inundating him in notional complexity.

Baker and Kaplan (1994: 3) contend that translators rarely manage to insert dictionary equivalents into the context of what they are translating. They point out that a better dictionary would be one which provides information about 
context and usage. Nelson (1978: 213) is in agreement with this sentiment when he argues that it would be better if lexicographers were to think contextually, rather than using simple one-to-one translations.

Gouws (1996: 16) also underscores the importance of context to support and supplement any translation equivalents supplied. He summarises the functions of the bilingual dictionary and bilingual lexicographer as follows:

Although bilingual dictionaries are employed as polyfunctional sources of semantic information, their main function is not a transfer of meaning. Bilingual dictionaries are aids in interlingual translations and have to focus on a treatment that enables the user to render a good and sound translation. The main aim of the dictionary should not only be the establishment of a relation of semantic equivalence between source and target language. Instead, a lexicographer has to endeavour to reach communicative equivalence.

\subsection{Lack of translation equivalents in the TL}

Both Zgusta (1971: 323) and Al-Kasimi (1983: 61) point out that a major problem the bilingual lexicographer has to contend with, is that the required equivalents cannot always be found in the TL. These writers identify the following instances where a language might not necessarily possess the required translational equivalents:

\subsubsection{Lexical units with other than designative function}

A lexical unit in the SL might not have a corresponding lexical unit in the TL. For example, the Zulu auxiliary verb stem -thi has only a grammatical function as carrier of tense, aspect, etc. when used together with an ideophone as in:

(3) Ngisathi shelele, ngizobuya masinyane nje 'I'm just slipping out (quickly), I'll be back shortly'.

In this context (i.e. used together with the ideophone shelele 'of going for a short while / slipping out'), the SL item -thi has no lexical equivalent in the TL.

\subsubsection{Culture-bound words}

These words denote objects or concepts peculiar to, for example, the SL culture, which would mean that such culture-bound items would have no translational equivalents in the TL. For example, the Zulu verb -lobola is explained by Doke et al. (1990: 460) as 'supplement a marriage by the handing over of some present of goods or of an agreed number of cattle (or money in lieu thereof) on the part of the bridegroom's people to the father or guardian of the bride, in order to ensure the right of the bridegroom to any issue of the marriage'. In order to overcome this problem of a lack of translational equivalent, lexicographers utilise the explanatory equivalent 'pass (over the) lobolo' in their illustrative 
sentences, where 'lobolo' is borrowed from Zulu ilobolo which is the corresponding noun formed from the verb stem -lobola. Mtuze (1990) illustrates that cultural issues could create problems for lexicographers because they might not comprehend certain concepts foreign to their own culture.

\subsubsection{Onomasiological gaps}

Apart from those words lacking translational equivalents as has been discussed here, so-called 'onomasiological gaps' in, for example, the TL are also caused by (scientific and technological) terminology in the SL which do not exist in the TL. Al-Kasimi (1983: 61) points out that a vocabulary can be expanded or extended in a number of ways as can be illustrated for Zulu by means of the following examples:

(4) Word borrowing, e.g. English computer Zulu ikhompiyutha

(5) Coinage, e.g. English nuclear fission Zulu ukucanda ubuphakathi bento

(Back-translation: 'to cleave the inside/nucleus of something' (Doke et al. 1990: 314))

(6) Giving new meaning to existing words, e.g.

English department (of education, etc.) Zulu umnyango (wemfundo, nj11.)

Note that the basic meaning of umnyango is 'door'.

(7) Extending the meaning of existing words, e.g.

English electricity Zulu ugesi

The meaning of ugesi has been extended from the original meaning 'coal gas (as used for lighting and heat)' now also to include the meaning 'electric light, lamp; electricity'.

(8) Compounding new words from existing elements from the language or from it and some other one, e.g.

English counterfeit coin Zulu imalimbumbulu

(< imali 'money' + mbumbulu 'counterfeit' (Doke et al. 1990: 480))

Apart from the lack of a translational equivalent in the TL as has been discussed here, there are also other instances of non-equivalence to be found between the SL and TL.

\subsection{Instances of non-equivalence between languages}

Al-Kasimi (1983: 63-67) identifies the following further instances of non-equivalence between languages that can all be illustrated with examples from Zulu as indicated in the paragraphs below. 
Languages differ in their related grammatical categories. For example, in the Bantu language family, the grammatical category 'noun' contains a division of nouns into up to 23 different noun classes which each has its own class prefix, indicating mainly singular and plural, but also other semantic notions such as abstract, diminutive, augmentative, locative, etc. This is very different from the word category 'noun' as found in, for example, English.

Languages differ in their parts of speech. For example, a language such as Zulu distinguishes the word category 'ideophone' which does not exist in a language such as English.

A lexical unit in one language may not have a corresponding lexical unit in another language. In Zulu the interrogative marker na? has no lexical equivalent in a language such as English. This interrogative marker corresponds to interrogative sentences indicated by only a question mark in English, e.g.

\section{Uyasebenza na? 'Are you working?'}

Two languages may have different grammatical patterns to determine certain aspects of experience. A Zulu sentence such as Uhambile can mean either 'He/ she is gone' or 'He/she has gone/left' in English. Some supplementary information is therefore needed in order to arrive at an adequate English translation.

One of two corresponding words in different languages may have undesirable connotations. In Zulu umfazi signifies not only '(married) woman', but also has the added connotation of 'wife'. It may also sometimes be used as a term of insult for a loose woman (Doke et al. 1990: 201). Because of this negative connotation in certain contexts, it should therefore be avoided as a general term for 'woman'.

A lexical unit in one language may have two or more components whilst its equivalent in another language may have only one component. For example, Zulu Sala kahle and Hamba kahle correspond to English (Good)bye, whilst Zulu Sawubona corresponds to English Hello, Good day, Good morning, Good afternoon and Good evening.

Two related items in two different languages may not cover the same semantic range as in the case of the Zulu word umuthi which represents both 'tree' and 'medicine' in English.

Substantives and adjectives in the TL may not always be considered as equivalents of the substantives and adjectives of the SL. Whereas Zulu nouns and so-called 'relative' adjectives derived from those nouns differ morphologically (as in example (10)(a) below), this is not always the case in English where the same word may function as noun and adjective (as in example (10)(b) below):

(10) (a) Zulu amanzi (n) 'water', but -manzi (a) 'wet', e.g. indwangu emanzi 'a wet cloth'

(b) English stone (n), and stone (a), e.g. stone wall 
Idioms and figures of speech, i.e. exocentric expressions, create special difficulties for the bilingual lexicographer as a certain amount of adaptation is necessary for the translation of these expressions. A metaphor in the SL cannot simply be translated with a corresponding metaphor in the TL. For example, the English metaphor Adam's apple cannot be translated by way of a metaphor in Zulu, as such a metaphor does not exist. (The Zulu equivalent for 'Adam's apple' is the term igilo.) Mtuze (1990: 32) points out that idioms and other figurative expressions have become so fixed by usage in a particular language that it is very difficult or even impossible to render them in another language.

Swanepoel (1989: 216-217) indicates that languages also differ from each other regarding the presuppositions or connotations underlying lexical items. For example, the nearest translational equivalents for the Zulu word umthakathi is English 'witch, wizard, warlock'. There is, however, a significant difference between what is understood by the concept of practising witchcraft and the person who indulges in this type of practice within the Zulu culture, and the connotations associated with English 'witch, wizard, warlock'. Similarly, the translation of Zulu isangoma ('diviner') with English 'witchdoctor' ignores the fact that the practice of the diviner has nothing in common with witchcraft as either practised by the umthakathi within Zulu culture, or understood within Western culture. The connotations or presuppositions underlying the various words within the different cultures are therefore completely divergent.

Swanepoel (1989: 219) indicates that, because of problems such as have been discussed here regarding lack of translational equivalents, as well as the non-equivalence between languages, translators cannot reasonably expect the bilingual dictionary to provide them with translation equivalents that can be inserted directly into a TL text. Rather, the bilingual dictionary will provide translators with translational equivalents in a limited number of cases, and with explanatory equivalents and explanations in the majority of cases. It is furthermore essential that the bilingual dictionary should provide adequate examples illustrating the various contexts in which a specific word can be used.

Mtuze (1990: 32) points out that equivalence is 'a rather difficult ideal' for the lexicographer. Neubert (1992: 1) refers to the lexicographer's dilemma which 'consists simply in his brave attempt to do the impossible'. Mtuze (1990: 32) states:

At best, we try to maintain adequacy [...] by which we mean that the target language version is not $100 \%$ equivalent to the source language version but that it is, on the whole, a fair reflection of the original.

Adamska-Sałaciak (2006: 20) stresses the following inevitable paradox which renders bilingual dictionaries a contradiction in terms:

[...] bilingual dictionaries are impossible in theory, but indispensable and irreplaceable in practice.

From the preceding discussion, it is clear that there are many and varying problems the bilingual lexicographer has to deal with and take cognisance of 
when compiling a translation dictionary. Of these, the main problem would seem to be the basic anisomorphism or lack of equivalence which exists between languages.

This non-equivalence between languages is also the root cause of the difficulties with which the translator or user of the bilingual dictionary has to contend.

\section{Problems experienced by translators}

The problems experienced by translators overlap to a great extent with those problems the lexicographer experiences in compiling a bilingual dictionary.

\subsection{The nature of bilingual dictionaries - what the user should know}

According to Pinchuck (1977: 223), the translator should bear in mind

(a) that a dictionary, and therefore also a bilingual dictionary, is always out of date;

(b) that many of the recorded expressions are no longer in common use;

(c) that expressions referred to as colloquial or non-standard may have risen into more formal use; and

(d) that, most commonly, new expressions have come into use but are not yet recorded.

Pinchuck points out that the dictionary therefore has limitations, but if used intelligently, it can be of great value, and indeed indispensable.

Neubert (1992: 1 et seq.) argues for a realistic attitude of the user towards the bilingual dictionary. Such a realistic attitude, Neubert believes, will be determined by the following factors:

(a) Entries should be appreciated as constituting pieces of text which provide the user with directions on how to use target words as substitutes for source words.

(b) The user should be aware of the 'default settings' of the dictionary, i.e. who the dictionary is aimed at / directed towards. Bilingual dictionaries cannot present the same information both ways, i.e. to L1 as well as to L2 speakers. The bilingual dictionary further constantly has to choose between either defining the meaning of an L1 item, or translating it by way of L2 material.

(c) The translation(s) selected by the bilingual lexicographer as L2 equivalents should never be mistaken for the translation(s) of an L1 item. Such translational equivalents should rather be regarded as prototypical lexical patterns, directing the user to look in a certain direction for more 
appropriate L2 equivalents. Neubert (1992: 6) states that this extra work on the part of the user is decisive. Neubert (1992: 7) rightly says:

The term translation dictionary does not entail that it offers the needed translation. It points the way to the translation, no more. Who thinks otherwise [...] takes fiction for fact.

As was also mentioned at the outset of this article, Swanepoel (1989: 203) states that the translation dictionary is merely a useful aid to professional translators in cases where their acquired knowledge of the second language is lacking. Swanepoel (1989: 203-204) further indicates that the translation dictionary does not immediately supply the most suitable equivalent for a certain context, but rather a collection of expressions in the TL from which the user must make a choice, or which may be used as a guideline in searching for the most suitable translation equivalent. Swanepoel points out that users of a translation dictionary must

(a) know exactly what they are looking for in a translation dictionary, i.e. users must know how to interpret and evaluate the information given, and how to relate it to their specific usage tasks; and

(b) know how to execute further searches in a specific translation dictionary and in other sources such as monolingual dictionaries in the TL and SL.

\subsection{Shortcomings of the bilingual dictionary}

Baker and Kaplan (1994: 2-3) indicate that dictionaries available to the translator tend to be found at opposite ends of the spectrum. At the one end, there are bilingual dictionaries which offer equivalent words and phrases, rather than explain the meanings of headwords. At the other end, there are the monolingual dictionaries which, irrespective of whether they are intended for mother tongue speakers or second language learners, tend to rely on synonyms. A new range of so-called 'semi-bilingual' dictionaries contain a combination of equivalents and synonyms. Baker and Kaplan are critical of the usefulness of dictionaries to the translator, as translators in real life work with genuine communicative events at the level of discourse, rather than with neat abstractions. Translators therefore rarely manage to insert dictionary equivalents into the context of what they are translating. As was mentioned earlier, Baker and Kaplan believe that a better dictionary is one that provides information about context and usage. This sentiment is echoed by Gouws (1996: 16-17):

Where the specific contexts in which translation equivalents can be used to substitute the lemma are not given as part of the lexicographical treatment, it is hardly possible that the creation of semantic equivalence can lead to the establishment of communicative equivalence. [...] Lack of additional information impedes the possibility to reach communicative equivalence; the form of equivalence that should be the lexicographer's first priority. 
Pinchuck (1977: 225) indicates that ideally a dictionary should be an instrument of semantic discrimination which enables the user to choose between words for a given application. A dictionary should also offer information about the position of a word within a series and its value within a lexical structure. He argues, however, that this function is performed crudely in existing dictionaries, mainly because of the arbitrary arrangement of items from the linguistic and conceptual points of view. He contends that the dictionary presents the language as an inventory - as a list of words unconnected with one another, instead of offering it as a structured and patterned system, which is the way words are used in practice.

Pinchuck (1977: 232) argues that in a bilingual dictionary, neither the definition nor the single word equivalent meets the needs of translation. Should the dictionary provide long definitions, they are frustrating to the user who wants a word. Should the dictionary provide a single translation equivalent, it would also not be satisfactory, as it is bound to be a selection from a series of possible alternatives. Such a selection would then have been made according to the arbitrary judgement of the compiler. The ideal would therefore be the mapping out of the whole area of signification of the words of the language, by means of a series of equivalents. Such equivalents will not only serve to make the meanings and usage clear, but will provide or suggest the exact or most appropriate translation for the context in which the user has seen or heard a word or phrase.

Pinchuck (1977: 233) further points out that the bilingual dictionary depends for its comprehension on the maximum possible co-operation of the user, and relies on users' understanding of their mother tongue. Pinchuck therefore concludes that, in the light of these factors, the bilingual dictionary should only be used as a last resort.

Despite the shortcomings of the bilingual dictionary as listed in this section, bilingual dictionaries can be of considerable use to the translator provided that

(a) the translator knows what to expect and what not to expect from a translation dictionary; and

(b) the dictionary consulted is a good one that meets with certain set requirements.

\subsection{Advantages of the bilingual dictionary}

To summarise, Pinchuck (1977: 234) lists the main features of a good bilingual dictionary as follows:

(a) The dictionary should provide correct translation equivalents, despite the difficulties inherent in bilingual lexicography as discussed so far in this article. 
(b) The dictionary should furnish as wide a range of application as possible for each item - the range will never be wide enough.

(c) The dictionary should detail full grammatical information regarding word class, inflectional and derivational forms, and syntactic restrictions and applications.

(d) The dictionary should give the level of usage of the equivalents provided.

As mentioned before, Baker and Kaplan (1994) are critical of existing bilingual dictionaries. Baker and Kaplan (1994: 8) further indicate that because of the basic lack of equivalence or anisomorphism existing between languages, an SL word or expression may not have a straightforward equivalent in the TL. They argue that such a state of affairs reflects the realities of translation where space restrictions and the need to communicate the message succinctly, rather than by way of a long exposition, are important considerations in almost any kind of translational activity.

Baker and Kaplan argue in favour of a new type of bilingual dictionary, the so-called 'bridge bilinguals'. According to Baker and Kaplan (1994: 1), bridge bilinguals are translated versions of monolingual dictionaries in which the explanation is translated into the TL / the user's mother tongue. Baker and Kaplan (1994: 3) point out that the advantage of this type of dictionary is that it provides far more information about the behaviour and meaning of the defined item than would be found in a conventional bilingual dictionary. Baker and Kaplan (1994: 5) indicate that in this type of dictionary, the use of equivalents to replace translated explanations are avoided as a rule, except where an explanation would irritate the user as a ready equivalent would provide the same information in a compact and more accessible form. Baker and Kaplan (1994: 6) give the following criteria for deciding when to replace an explanation with an equivalent:

(a) The equivalent must be a high frequency word in the TL.

(b) The TL equivalent cannot be a polysemous word; it must have one meaning only.

(c) The TL equivalent should replace the headword in a translated version of the example(s) which follow the explanation.

(d) The TL equivalent should not be a loanword with a different meaning in the SL.

(e) The TL equivalent should have the same use as the headword.

Baker and Kaplan (1994: 9) indicate that bridge bilinguals are not only helpful as tools for language learning, but that they are also useful to professional translators as they provide translations of examples. Bridge bilinguals can be regarded as genuine translation assignments that are either undertaken by professional translators, or at least monitored and assessed by them. Teams en- 
gaged in writing such bridge bilinguals, work to the same kind of brief as most translators, which entails that they

(a) are commissioned by a client;

(b) have a specific group of prospective users in mind;

(c) are aware of the function the target text is meant to fulfil; and

(d) adhere to fairly strict deadlines.

\section{Conclusion}

In this article, the various problems confronting the bilingual lexicographer as well as the translator using bilingual dictionaries have been detailed and discussed. It is clear that underlying all of these problems is the basic lack of equivalence or anisomorphism between languages. It is also evident that users of bilingual dictionaries should not only know what they can expect to find in a translation dictionary, but must also treat such a dictionary with circumspection and discernment. It was also shown that there are clear criteria which the lexicographer can follow in compiling a bilingual dictionary, which would then enable the user (and specifically the translator as user) to disambiguate the recorded information with great success.

\section{References}

Adamska-Sałaciak, A. 2006. Meaning and the Bilingual Dictionary. The Case of English and Polish. Frankfurt am Main: Peter Lang.

Al-Kasimi, A.M. 1983. Linguistics and Bilingual Dictionaries. Leyden: E.J. Brill.

Baker, M. and R. Kaplan. 1994. Translated! A New Breed of Bilingual Dictionaries. Babel 40(1): 1-11.

Doke, C.M., D.M. Malcolm, J.M.A. Sikakana and B.W. Vilakazi. 1990. English-Zulu Zulu-English Dictionary. Johannesburg: Witwatersrand University Press.

Gouws, R.H. 1996. Bilingual Dictionaries and Communicative Equivalence for a Multilingual Society. Lexikos 6: 14-31.

Manning, A. 1990. The Role of Dictionaries and Context in the Translation Process: The Canadian Connection. Thelen, M. and B. Lewandowska-Tomaszczyk. Translation and Meaning. Part 1: 59-166. Maastricht: Euroterm.

Mtuze, P. 1990. Problems of Equivalence and Adequacy in a Trilingual Context. South African Journal of Linguistics 8(1): 30-32.

Nelson, R.J. 1978. Translation and Translating Dictionaries. The Incorporated Linguist 17(2): 36-37.

Neubert, A. 1992. Fact and Fiction of the Bilingual Dictionary. EURALEX '90 Proceedings. IV International Congress: 29-42. Barcelona: Biblograf.

Nida, E.A. 1958. Analysis of Meaning and Dictionary Making. International Journal of American Linguistics 24: 279-292.

Pinchuck, I. 1977. Scientific and Technical Translation. London: Deutsch.

Swanepoel, P.H. 1989. Only Study Guide for LEKPER-Q. Pretoria: University of South Africa.

Zgusta, L. 1971. Manual of Lexicography. The Hague/Paris: Mouton. 